\title{
NOTE
}

\section{Measurement of chlorine stable isotopic composition by negative thermal ionization mass spectrometry using total evaporation technique}

\author{
TATSUYA FUJitani, ${ }^{1,2 *}$ KatsuyUKi Yamashita, ${ }^{2,3}$ Masahiko Numata, ${ }^{4}$ \\ NOBUYUKI KANAZAWA ${ }^{5}$ and NOBORU NAKAMURA ${ }^{2}$ \\ ${ }^{1}$ Marine Technical College, Ashiya 659-0026, Japan \\ ${ }^{2}$ Department of Earth and Planetary Sciences, Kobe University, Kobe 657-8501, Japan \\ ${ }^{3}$ The Pheasant Memorial Laboratory, Institute for Study of the Earth's Interior, Okayama University, \\ Misasa, Tottori 682-0193, Japan \\ ${ }^{4}$ National Metrology Institute of Japan, AIST, Tsukuba, Ibaraki 305-8563, Japan \\ ${ }^{5}$ Thermo Fisher Scientific K.K., Moriya, Yokohama 221-0022, Japan \\ (Received May 9, 2009; Accepted August 7, 2009)
}

\begin{abstract}
A total evaporation negative thermal ionization mass spectrometry (TE-N-TIMS) technique for the isotopic analysis of chlorine was developed. This technique provides fast and reliable way to determine the isotopic signature of chlorine samples as small as $100 \mathrm{ng}$. Compared to the conventional N-TIMS method, the precision of the $\mathrm{Cl}$ isotopic analysis is improved by a factor of up to 3 by minimizing the effect of mass fractionation. Using this method, reproducibility of $0.9 \%$ (R.S.D.: $n=25$ ) can be achieved for ${ }^{37} \mathrm{Cl} /{ }^{35} \mathrm{Cl}$ ratio of $200 \mathrm{ng} \mathrm{Cl}$. The analyzed results of the $\mathrm{AgCl}$ reagent expressed as a per-mil deviation $\left(\delta^{37} \mathrm{Cl}\right)$ relative to the Standard Mean Ocean Chloride showed good concordance with the value obtained by conventional positive thermal ionization mass spectrometry (P-TIMS).
\end{abstract}

Keywords: chlorine stable isotopes, total evaporation method, negative thermal ionization mass spectrometry, small samples

\section{INTRODUCTION}

Chlorine, which is one of the representative volatile elements in the earth's surface environment, has two stable isotopes ${ }^{35} \mathrm{Cl}$ and ${ }^{37} \mathrm{Cl}$, with relative abundances of approximately $75 \%$ and $25 \%$, respectively. The chlorine isotopic variations observed in geological and environmental samples are often used to trace the migration processes of volatile chemical species, or chemical reactions of chlorinated organic compound in the earth's surface environment (Stewart and Spivack, 2004). Determination of the isotopic composition of chlorine has been carried out by $\mathrm{CH}_{3} \mathrm{Cl}^{+}$gas mass spectrometry (IRMS) (Kaufmann et al., 1984), $\mathrm{Cs}_{2} \mathrm{Cl}^{+}$thermal ionization mass spectrometry (P-TIMS) (Xiao and Zhang, 1992; Numata et al., 2001) and $\mathrm{Cl}^{-}$negative thermal ionization mass spectrometry (N-TIMS) (Vengosh et al., 1989). The former two methods can offer high analytical precision (normally 0.1$0.5 \%$ in ${ }^{37} \mathrm{Cl} /{ }^{35} \mathrm{Cl}$ ratio). The IRMS method, however, requires a large amount of chlorine $(>1 \mathrm{mg})$ for each

\footnotetext{
*Corresponding author (e-mail: fujitani@mail.mtc.ac.jp)

Copyright (c) 2010 by The Geochemical Society of Japan.
}

measurement. Even the P-TIMS method requires microgram quantity of $\mathrm{Cl}$ for precise analysis. For this reason, these two methods have been applied to the isotopic analysis of relatively large samples, or samples with high $\mathrm{Cl}$ concentration such as fluid inclusion in ore deposits (Eastoe and Guilbert, 1992), evaporites (Eggenkamp et al., 1995), Cl-bearing silicate minerals (Willmore et al., 2002) and Cl-rich metamorphic rocks (Barnes and Sharp, 2006; Bonifacie et al., 2008). The N-TIMS technique, on the other hand, provides much higher sensitivity for chlorine relative to IRMS and P-TIMS, and only several hundred nano-grams of $\mathrm{Cl}$ is necessary (Fujitani and Nakamura, 2006). However, its analytical precision is worse than the former two methods mainly due to the effect of isotopic fractionation during the evaporation and ionization processes (normally in the order of few \%o).

Previous studies have demonstrated the existence of large isotopic fractionation of chlorine during geological process (Stewart and Spivack, 2004; Godon et al., 2004). If the precision of $\mathrm{Cl}$ isotopic analysis for the N-TIMS can be improved, it will provide the opportunity to investigate the chlorine isotopic composition of small samples that cannot be studied with the IRMS and P-TIMS methods. One candidate to improve the precision for N-TIMS 
is to adopt the total evaporation method, where the ion beam of each isotope from a sample on the filament is simultaneously integrated until the sample evaporates completely. Because the entire beam is integrated, the effect of isotopic fractionation during the data acquisition is minimized. The total evaporation method using thermal ionization mass spectrometry has been developed for the isotopic analysis of uranium and plutonium in the nuclear industries (Callis and Abernathey, 1991), and neodymium in small samples (Wakaki et al., 2007). The first application of isotopic analysis using total evaporation technique in a negative ion mode was the analysis of Re isotopes (Suzuki et al., 2004). In this study, the total evaporation negative thermal ionization mass spectrometry (TE-N-TIMS) is applied to the analysis of chlorine stable isotope and its analytical effectiveness is discussed in detail.

\section{EXPERIMENTAL}

\section{Reagents and seawater}

The chloride mounted onto the filament for TE-NTIMS was ammonical solution of $\mathrm{AgCl}$ (Vengosh et al., 1989). The standard solution for this study was prepared by dissolving $\mathrm{AgCl}$ (Wako Pure Chemical Industries Ltd.) reagent with aqueous ammonia solution (30\%, Kanto Chemical Co.) as shown below.

$$
\mathrm{AgCl}+2 \mathrm{NH}_{3} \rightarrow \mathrm{Ag}\left(\mathrm{NH}_{3}\right)_{2} \mathrm{Cl} .
$$

The $\mathrm{Cl}$ concentration of the solution was adjusted to approximately $100 \mathrm{mg} \mathrm{L}^{-1}$. The seawater sample was taken from the Pacific Ocean $\left(8^{\circ} 39.5^{\prime} \mathrm{N}, 153^{\circ} 56.6^{\prime} \mathrm{E}\right.$, surface) (Numata et al., 2001). The chlorine ion in the seawater was precipitated as $\mathrm{AgCl}$ by addition of $0.03 \mathrm{M} \mathrm{AgNO}_{3}$ solution in a dark room. The precipitate was then dissolved in the ammonia solution. By using ion chromatography, we confirmed that more than $94 \%$ of the chlorine in the seawater was recovered in the sample solution. The water used in this chemical procedure was obtained from a Millipore Milli-Q water purification system.

\section{Mass spectrometry}

The isotopic ratios of chlorine were measured using a Finnigan MAT262 thermal ionization mass spectrometer equipped with five Faraday detectors. The resistance of the Faraday cup amplifier was $10^{11} \Omega$ and a beam intensity of $1 \mathrm{~V}$ corresponds to $10^{-11} \mathrm{~A}$. The operating condition for mass spectrometry is similar to the negative thermal ionization mass spectrometry for isotope dilution analysis of $\mathrm{Cl}$ described in Fujitani and Nakamura (2006). $\mathrm{Re}-\mathrm{Re}$ double filament assemblage using zone-refined $\mathrm{Re}$ ribbons $(0.025 \times 0.75 \mathrm{~mm}$; purity: $99.999 \%$; H. CROSS
Co.) was employed for the TE-N-TIMS analysis. About $2 \mu \mathrm{L}$ standard solution containing $200 \mathrm{ng}$ of chlorine was deposited onto a degassed flat Re filament and slowly evaporated to dryness at low filament current $(\sim 0.7 \mathrm{~A})$. Filaments with $100 \mathrm{ng}$ and $500 \mathrm{ng} \mathrm{Cl}$ were also prepared. For the seawater, the amount of $\mathrm{Cl}$ loaded onto the filament was $200 \mathrm{ng}$. The filament was then assembled into the mass spectrometer for isotopic measurement. The accelerating voltage was set to $-10 \mathrm{kV}$.

Only the ionization filament (Io) current was increased automatically up to $1.8 \mathrm{~A}$, which corresponds to filament temperature of about $1300^{\circ} \mathrm{C}$. The sample (evaporation) filament (Ev) was fixed at $0 \mathrm{~A}$ throughout the analysis. When the ${ }^{35} \mathrm{Cl}^{-}$ion beam was observed in ion counting mode, the beam was focused and the filament current was increased manually until the intensity of the ${ }^{35} \mathrm{Cl}^{-}$ion beam reached $2 \mathrm{mV}$.

The data acquisition was performed in a multi-collector static mode to simultaneously collect ${ }^{37} \mathrm{Cl}^{-}(\mathrm{m} / \mathrm{z}=37)$ and ${ }^{35} \mathrm{Cl}^{-}(\mathrm{m} / \mathrm{z}=35)$. Once the data acquisition started, the filament current was automatically increased at a rate of $30 \mathrm{~mA} / \mathrm{scan}$ until the ${ }^{35} \mathrm{Cl}^{-}$ion beam intensity reached a preset maximum value. The preset maximum values were adjusted to $120 \mathrm{mV}$ for $500 \mathrm{ng} \mathrm{Cl}, 100 \mathrm{mV}$ for 200 $\mathrm{ng} \mathrm{Cl}$ and $80 \mathrm{mV}$ for $100 \mathrm{ng} \mathrm{Cl}$, respectively, in order to evaporate the sample entirely within 100 to 200 scans. If the intensity increased beyond the preset value, the filament current was reduced or kept nearly constant in order to keep the ion beam intensity nearly constant. Integration time of 1 scan was 4 seconds.

When most of the sample was evaporated from the sample filament, the ion beam intensity decreased rapidly. The data acquisition was terminated when the ${ }^{35} \mathrm{Cl}^{-}$ ion beam intensity fell below a preset threshold value of $5 \mathrm{mV}$. The final isotope ratio was calculated from the integrated ion intensities of each isotope after subtraction of the baseline intensity. Because the entire beam is integrated to calculate the isotope ratio, the analytical error for each analysis is not available. The time required for each analysis is less than twenty minutes.

For the comparison of the data, we have undertaken isotopic analyses of the $\mathrm{AgCl}$ reagent and seawater using P-TIMS method. The details of the analytical technique for P-TIMS are described in Numata et al. (2001).

\section{RESUltS AND DisCUSSION}

A typical profile of ${ }^{35} \mathrm{Cl}^{-}$ion beam intensity and its corresponding filament current as a function of scan number is shown in Fig. 1a. In this example, the sample on the filament was totally evaporated after 166 scans. The beam intensities of both ${ }^{35} \mathrm{Cl}^{-}$and ${ }^{37} \mathrm{Cl}^{-}$ions rose rapidly up to the preset value, where it was held until most of the sample was evaporated. The filament current also 

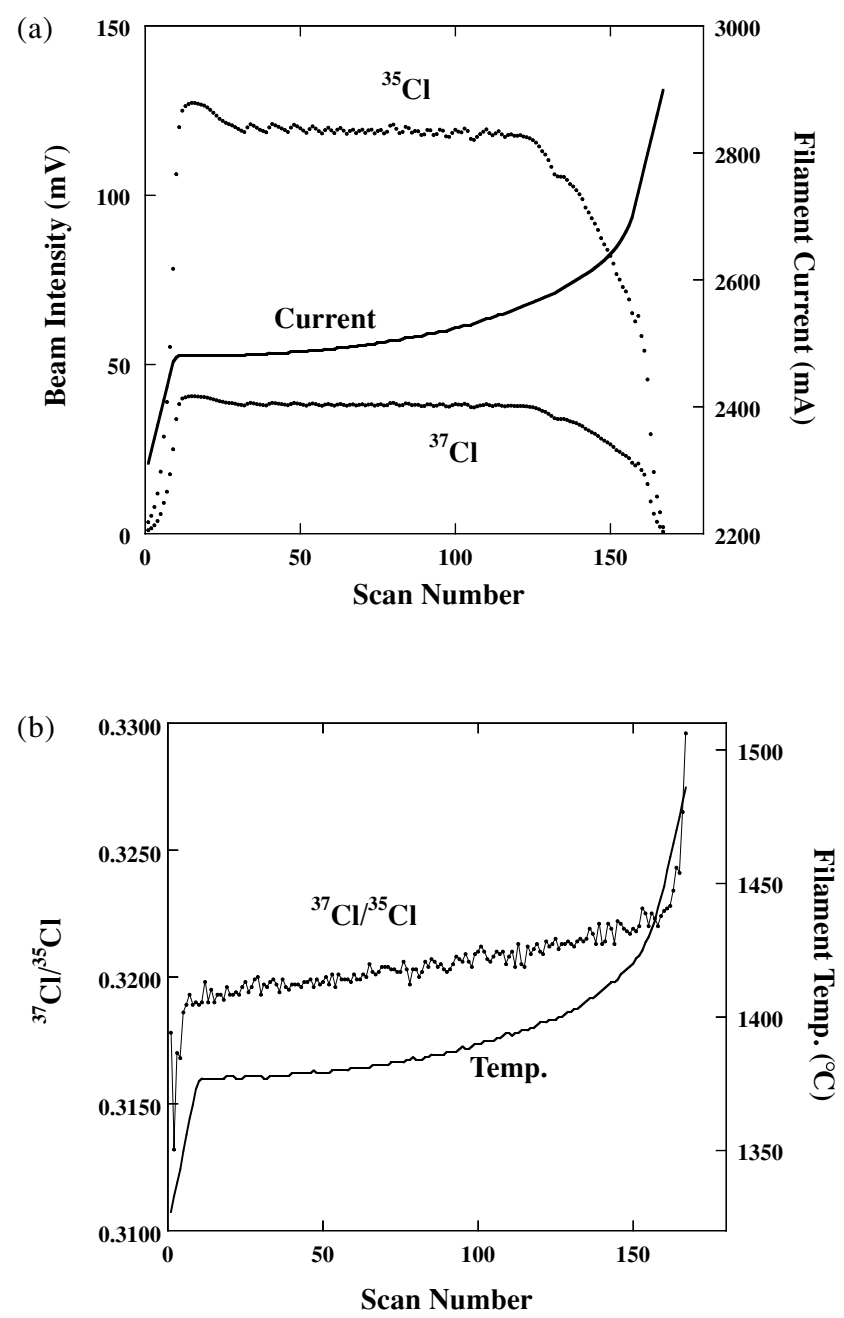

Fig. 1. (a) The representative profiles of the ${ }^{35} \mathrm{Cl}^{-}$and ${ }^{37} \mathrm{Cl}^{-}$ ion beam intensities for $500 \mu \mathrm{g} \mathrm{Cl} \mathrm{sample} \mathrm{and} \mathrm{the} \mathrm{filament} \mathrm{cur-}$ rent during the total evaporation procedure against the scan number. (b) The fluctuations of ${ }^{35} \mathrm{Cl} /{ }^{37} \mathrm{Cl}$ ratio and their corresponding filament temperature against the scan number for the same analysis in $(a)$.

rose rapidly until the preset beam intensity but gradually increased during the analysis to keep the beam intensity constant. When the filament current reached around 2600 $\mathrm{mA}$, the ion beam intensity dropped suddenly.

Figure $1 \mathrm{~b}$ shows the fluctuation of ${ }^{37} \mathrm{Cl} /{ }^{35} \mathrm{Cl}$ and its corresponding filament temperature of the same sample shown in Fig. 1a. The ${ }^{35} \mathrm{Cl}^{-}$ion beam intensity reached its preset value at approximately $1380^{\circ} \mathrm{C}$. At this temperature, the effect of isotopic fractionation was already apparent. Isotopic fractionation gradually proceeded as the filament current increased. It is noteworthy that the isotopic fractionation of chlorine began at a much lower temperature of around $1340^{\circ} \mathrm{C}$ (Fujitani and Nakamura, 2006). This may be the reason why conventional N-TIMS
Table 1. Results of the Cl isotope composition of $\mathrm{AgCl}$ reagent (Cl content $200 \mathrm{ng}$ )

\begin{tabular}{rrc}
\hline Run \# & ${ }^{35} \mathrm{Cl}$ total voltage $(\mathrm{V})$ & ${ }^{37} \mathrm{Cl}{ }^{\beta 5} \mathrm{Cl}$ \\
\hline 1 & 5.28 & 0.32118 \\
2 & 6.81 & 0.32025 \\
3 & 9.89 & 0.32098 \\
4 & 10.69 & 0.32054 \\
5 & 4.90 & 0.32051 \\
6 & 7.95 & 0.32114 \\
7 & 11.46 & 0.32052 \\
8 & 4.45 & 0.32087 \\
9 & 6.32 & 0.32088 \\
10 & 5.10 & 0.32027 \\
11 & 8.84 & 0.32078 \\
12 & 5.07 & 0.32058 \\
13 & 8.80 & 0.32113 \\
14 & 7.08 & 0.32070 \\
15 & 6.68 & 0.32046 \\
16 & 5.50 & 0.32066 \\
17 & 7.48 & 0.32052 \\
18 & 6.68 & 0.32080 \\
19 & 5.85 & 0.32043 \\
20 & 3.63 & 0.32042 \\
21 & 13.87 & 0.32102 \\
22 & 5.56 & 0.32114 \\
23 & 5.35 & 0.32065 \\
24 & 20.13 & 0.32091 \\
25 & 15.11 & 0.32029 \\
& & \\
& Average $\pm 1 \mathrm{SD}$ & $0.32071 \pm 0.00029$ \\
& R.S.D. $(\%)$ & 0.9 \\
\hline
\end{tabular}

analysis could not provide highly reproducible chlorine isotopic data compared to other methods. Since the isotope ratio of TE-N-TIMS is derived from the integrated ion intensities of each isotope, the effect of isotopic fractionation is likely minimized.

The results of the chlorine isotopic compositions of the $200 \mathrm{ng} \mathrm{Cl}$ in $\mathrm{AgCl}$ reagent are given in Table 1 and Fig. 2. Isotopic measurements were carried out 25 times. The average number of scans was 110 and the average of the ${ }^{35} \mathrm{Cl}$ total voltage was approximately $7.9 \mathrm{~V}$. This corresponds to an electric charge of approximately $7.9 \times$ $10^{-11} \mathrm{C}$. The mean value of the ${ }^{37} \mathrm{Cl} /{ }^{35} \mathrm{Cl}$ ratios was 0.32071 and the reproducibility was 0.00029 (1SD), which corresponds to R.S.D. of $0.9 \%$. The $\mathrm{Cl}$ isotopic ratios of the $100 \mathrm{ng}$ and $500 \mathrm{ng} \mathrm{Cl}$ in $\mathrm{AgCl}$ reagent were also determined. The mean value of the ${ }^{37} \mathrm{Cl} /{ }^{35} \mathrm{Cl}$ ratios of thirteen measurements of $500 \mathrm{ng}$ sample was 0.32081 . The reproducibility was 0.00028 ( $1 \mathrm{SD}, n=13)$, which was the same as the reproducibility of the $200 \mathrm{ng} \mathrm{Cl}$ sample. The measurements of the $100 \mathrm{ng} \mathrm{Cl}(n=9)$ showed somewhat larger reproducibility of 0.00066 (R.S.D. $=2.0 \%$ ) compared to $200 \mathrm{ng}$ and $500 \mathrm{ng}$ samples, with the mean value of 0.32088 . While the reproducibility of $100 \mathrm{ng}$ analysis reaches $2 \%$, the reproducibility of $200-500 \mathrm{ng}$ 
Table 2. Measured $\mathrm{Cl}$ isotopic compositions and the deviation of the ${ }^{37} \mathrm{Cl} /{ }^{35} \mathrm{Cl}$ from the SMOC

\begin{tabular}{lccccc}
\hline Sample & Cl content (ng) & Number of run & $\begin{array}{c}\text { Average of }{ }^{35} \mathrm{Cl} \\
\text { total voltage }(\mathrm{V})\end{array}$ & ${ }^{37} \mathrm{Cl} /{ }^{35} \mathrm{Cl}$ & $\delta^{37} \mathrm{Cl}(\%)$ \\
\hline AgCl reagent & 100 & 9 & 2.9 & $0.32088 \pm 0.00066^{\text {a) }}$ & $+2.1 \pm 2.0^{\mathrm{b})}$ \\
& 200 & 25 & 7.9 & $0.32071 \pm 0.00029$ & $+1.5 \pm 0.9$ \\
& 500 & 13 & 25.4 & $0.32081 \pm 0.00028$ & $+1.8 \pm 0.9$ \\
Seawater & 200 & 9 & 4.7 & $0.32022 \pm 0.00036$ & $0 \pm 1.1$ \\
Seawater (P-TIMS) & 2000 & 8 & & $0.31910 \pm 0.00010$ & $0 \pm 0.31$ \\
\hline
\end{tabular}

${ }^{a)} 1 S D,{ }^{b)}$ R.S.D.

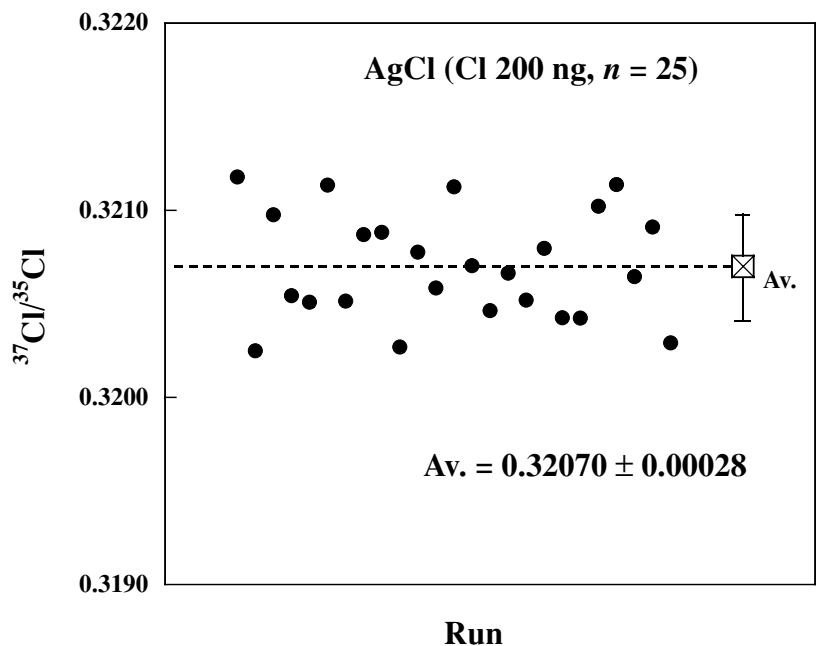

Fig. 2. The results of measurements of the chlorine isotope compositions in AgCl reagent. $200 \mathrm{ng} \mathrm{Cl}$ was loaded onto the filament. Error bar shows $1 S D$.

$\mathrm{Cl}$ is significantly better than that of conventional N-TIMS analysis (Vengosh et al., 1989). Furthermore, the isotopic compositions of all three cases showed good agreement, implying that the amount of $\mathrm{Cl}$ loaded onto the filament did not affect the result of the final data if they were kept in the range of 100 to $500 \mathrm{ng}$.

The $\mathrm{Cl}$ isotopic composition of seawater was also determined to serve as the Standard Mean Ocean Chloride (SMOC) reference standard (Kaufmann et al., 1984). The amount of chlorine used to determine the isotopic composition of the seawater sample was fixed at $200 \mathrm{ng}$. The mean value of the ${ }^{37} \mathrm{Cl} /{ }^{35} \mathrm{Cl}$ ratios obtained from nine repeated analyses was 0.32022 and the reproducibility was 0.00036 (R.S.D $=1.1 \%$ ).

The isotopic data for the samples analyzed during the course of this study are summarized in Table 2. The final $\mathrm{Cl}$ isotopic ratio of the sample is expressed as a per-mil deviation $\left(\delta^{37} \mathrm{Cl}\right)$ relative to SMOC. In order to check the quality of the data obtained by TE-N-TIMS method, the ${ }^{37} \mathrm{Cl} /{ }^{35} \mathrm{Cl}$ ratios of the $\mathrm{AgCl}$ reagent and seawater were

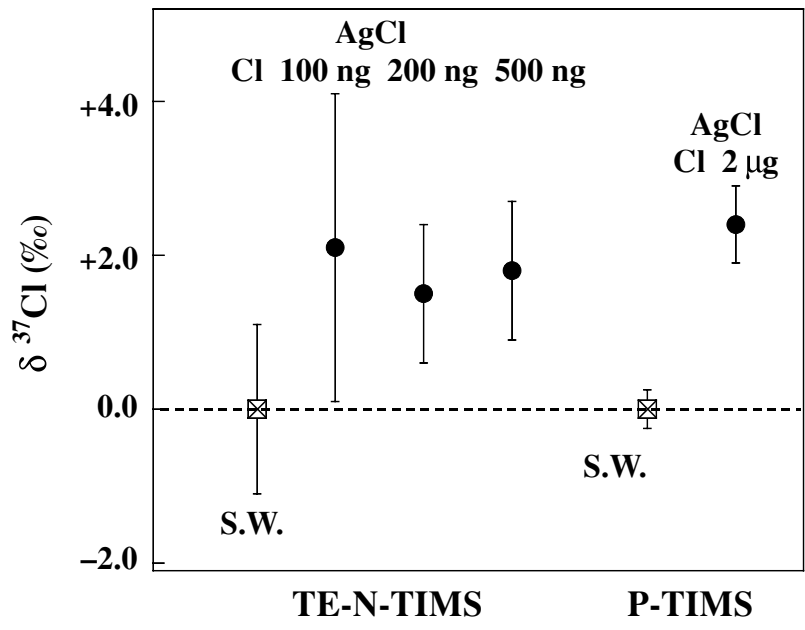

Fig. 3. The $\delta^{37} \mathrm{Cl}$ of chlorine isotope measurements of $\mathrm{AgCl}$ reagent by different technique, namely $N$-TIMS using total evaporation method and the conventional P-TIMS. Error bars refer to ISD. S.W., seawater.

also determined by P-TIMS. Chlorine loaded onto the filament for P-TIMS analysis was about $2 \mu \mathrm{g}$. The results were $0.31988 \pm 0.00017$ for the $\mathrm{AgCl}$ reagent and 0.31910 \pm 0.00010 for the seawater, respectively. The absolute values of $\mathrm{Cl}$ isotopic compositions analyzed by P-TIMS were $2.5 \sim 3.5 \%$ o lower than those of the total evaporation technique for both $\mathrm{AgCl}$ reagent and seawater. However, in most geological and environmental applications, we are only concerned about relative difference in $\mathrm{Cl}$ isotopic signatures, typically expressed as the deviation from the SMOC. The $\delta^{37} \mathrm{Cl}$ value of the $\mathrm{AgCl}$ reagent analyzed by P-TIMS method was $2.4 \pm 0.5 \%$. This is within the range of reproducibility of the values determined using TE-N-TIMS method, confirming the reliability of the technique (see Fig. 3).

Conventional IRMS and P-TIMS measurements have revealed a large fractionation of $\mathrm{Cl}$ isotopic composition during geological process, ranging from $-14 \%$ o to $+16 \%$ o in $\delta^{37} \mathrm{Cl}$ value (Godon et al., 2004). Recently, Sharp and co-workers have performed an IRMS analyses of MORB 
glasses and abyssal peridotites and argued that there is no large difference in the chlorine isotope signature between mantle and crustal materials, both of which have $\delta^{37} \mathrm{Cl}$ values close to $0 \%$ (Barnes and Sharp, 2006; Sharp et al., 2007). On the other hand, Wei et al. (2008) reported $\delta^{37} \mathrm{Cl}$ values of +1.2 to $+6.0 \%$ from serpentines from the subduction zones using P-TIMS. TE-N-TIMS may serve as the third method of the chlorine isotopic analysis to clarify such a discrepancy.

In addition to the reduced sample size for analysis, TE-N-TIMS has two additional advantages over IRMS and P-TIMS. One is the simple chemical procedure for sample preparation. The three different methods follow a common chemical procedure until the purification of chlorine from the samples by precipitation of $\mathrm{AgCl}$. While no further purification is necessary for N-TIMS analysis, PTIMS and IRMS techniques require additional troublesome procedures to convert the $\mathrm{Cl}^{-}$ions into the $\mathrm{Cs}_{2} \mathrm{Cl}^{+}$ ions or $\mathrm{CH}_{3} \mathrm{Cl}^{+}$ions, respectively. Second is the short analytical time required for mass spectrometry. Typical analytical time using TE-N-TIMS is about twenty minutes. This is a factor of ten shorter than the P-TIMS method.

The chlorine isotopic variation observed in the environmental pollutants such as chlorinated solvents (Numata et al., 2002) and perchlorates (Coates and Achenbach, 2004) is larger than that of typical geological samples. On the other hand, a large number of sample analysis is often necessary in the field of environmental chemistry. For this reason, a fast and simple analytical procedure developed in this study will be highly useful.

\section{CONCLUSION}

A fast and simple method for chlorine isotopic analysis using TE-N-TIMS was developed. Using this method, the ${ }^{37} \mathrm{Cl} /{ }^{35} \mathrm{Cl}$ ratio of $0.32071 \pm 0.00029$ (1SD) for $\mathrm{AgCl}$ reagent containing $200 \mathrm{ng}$ of $\mathrm{Cl}^{-}$was obtained. Reproducibility of $0.9 \%$ is slightly worse than that of the conventional thermal ionization mass spectrometry using $\mathrm{Cs}_{2} \mathrm{Cl}^{+}$ions. However, the sample size is reduced by a factor of ten, and the analytical time is also dramatically reduced. Although the absolute value of ${ }^{37} \mathrm{Cl} /{ }^{35} \mathrm{Cl}$ determined by the TE-N-TIMS does not perfectly match the value from the conventional P-TIMS, the per-mil deviation from the Standard Mean Ocean Chloride (SMOC) agrees within the analytical uncertainty, confirming the reliability of the method. The TE-N-TIMS method can therefore be used as a powerful tool in the study of very small amount of chlorine extracted from terrestrial and extraterrestrial samples. In addition, its simple analytical procedure and short analytical time will allow us to investigate a large number of samples, as required in the field of environmental sciences.
Acknowledgments-We thank Drs. T. Tanaka and K. Suzuki for helpful comments on the manuscript. This work was supported in part by Grants-in-Aid for Scientific Research (No. 1434017) from Ministry of Education, Culture, Sports Science and Technology of Japan.

\section{REFERENCES}

Barnes, J. D. and Sharp, Z. D. (2006) A chlorine isotope study of DSDP/ODP serpentinized ultramafic rocks: Insights into the serpentinization process. Chem. Geol. 228, 246-265.

Bonifacie, M., Busigny, V., Mevel, C., Philippot, P., Agrinier, P., Jendrzejewski, N., Scambelluri, M. and Javoy, M. (2008) Chlorine isotopic composition in seafloor serpentinites and high-pressure metaperidotites. Insights into oceanic serpentinization and subduction processes. Geochim. Cosmochim. Acta 72, 126-139.

Callis, E. L. and Abernathey, R. M. (1991) High-precision analyses of uranium and plutonium by total sample volatilization and signal integration. Int. J. Mass Spectrom. Ion Proc. 103, 93-105.

Coates, J. D. and Achenbach, L. A. (2004) Microbial perchlorate reduction: rocket-fuelled metabolism. Nature Rev. Microbiol. 2, 569-580.

Eastoe, C. J. and Guilbert, J. M. (1992) Stable chlorine isotopes in hydrothermal systems. Geochim. Cosmochim. Acta 56, 4247-4255.

Eggenkamp, H. G. M., Kreulen, R. and Koster van Groos, A. F. (1995) Chlorine stable isotope fractionation in evaporates. Geochim. Cosmochim. Acta 59, 5169-5175.

Fujitani, T. and Nakamura, N. (2006) Determination of chlorine in nine rock reference materials by isotope dilution mass spectrometry. Geostandard Geoanl. Res. 30, 113-120.

Godon, A., Webster, J. D., Layne, G. D. and Pineau, F. (2004) Secondary ion mass spectrometry for the determination of $\delta^{37} \mathrm{Cl}$ : Part I. Intercalibration of SIMS and IRMS for aluminosilicate glasses. Chem. Geol. 207, 291-303.

Kaufmann, R. S., Long, A., Bentley, H. and Davis, S. (1984) Natural chlorine isotope variations. Nature 309, 338-340.

Numata, M., Nakamura, N. and Gamo, T. (2001) Precise measurement of chlorine stable isotopic ratios by thermal ionization mass spectrometry. Geochem. J. 35, 89-100.

Numata, M., Nakamura, N., Koshikawa, H. and Terashima, Y. (2002) Chlorine stable isotope measurements of chlorinated aliphatic hydrocarbons by thermal ionization mass spectrometry. Anal. Chim. Acta 455, 1-9.

Sharp, Z. D., Barnes, J. D., Brearley, A. J., Fischer, T. P., Chaussidon, M. and Kamenetsky, V. S. (2007) Chlorine isotope homogeneity of the mantle, crust and carbonaceous chondrites. Nature 446, 1062-1065.

Stewart, M. A. and Spivack, A. J. (2004) The stable-chlorine isotope compositions of natural and anthropogenic materials. Rev. Mineral. Geochem. 55, 231-254.

Suzuki, K., Miyata, Y. and Kanazawa, N. (2004) Precise Re isotope ratio measurements by negative thermal ionization mass spectrometry (NTI-MS) using total evaporation technique. Int. J. Mass Spectrom. 235, 97-101.

Vengosh, A., Chivas, A. R. and McCulloch, M. T. (1989) Direct determination of boron and chlorine isotopic composi- 
tions in geological materials by negative thermal-ionization mass spectrometry. Chem. Geol. (Isotope Geosci. Sect.) 79, 333-343.

Wakaki, S., Shibata, S. and Tanaka, T. (2007) Isotope ratio measurements of trace Nd by the total evaporation normalization (TEN) method in thermal ionization mass spectrometry. Int. J. Mass Specrrom. 264, 157-163.

Wei, W., Kastner, M. and Spivack, A. (2008) Chlorine stable isotopes and halogen concentrations in convergent margins with implications for the $\mathrm{Cl}$ isotopes cycle in the ocean.
Earth Planet. Sci. Lett. 266, 90-104.

Willmore, C. C., Boudreau, A. E., Spivack, A. J. and Kruger, F. J. (2002) Halogens of the Bushveld Complex, South Africa: $\delta^{37} \mathrm{Cl}$ and $\mathrm{Cl} / \mathrm{F}$ evidence for hydration melting at the source region in a back-arc setting. Chem. Geol. 182, 503511.

Xiao, Y. K. and Zhang, C. G. (1992) High precision isotopic measurement of chlorine by thermal ionization mass spectrometry of $\mathrm{Cs}_{2} \mathrm{Cl}^{+}$ion. Int. J. Mass Spectrom. Ion Proc. 116, 183-192. 